\title{
Anísio Teixeira entre nós: A defesa da educação como direito de todos ${ }^{\star}$
}

\begin{abstract}
RESUMO: O objetivo do artigo é realizar uma reflexão sobre a vida e a obra de Anísio Teixeira (1900-1971), na comemoração do seu centenário de nascimento, destacando momentos decisivos da sua biografia, suas motivações como educador, aspectos da sua apropriação de John Dewey e a atualidade das suas concepções para pensar a educação brasileira contemporânea.
\end{abstract}

Clarice Nunes**

Palavras-chave: Educação brasileira, pensamento educacional brasileiro, trajetória de educadores

Os homens se amparam no coração de outros homens, sobretudo quando silenciados, perseguidos, acusados injustamente. Incompreendidos. Realçar a contribuição de Anísio Teixeira para a educação brasileira é, de certa forma, prestar uma homenagem não apenas a este grande educador, que pagou um alto preço pela defesa concreta e intransigente de que a educação não é privilégio, mas também tratar a educação do ângulo que mais a dignifica: o do direito social e da democratização de um ensino de qualidade, o da pesquisa qualificada e comprometida com os problemas sociais, o da organização de homens e instituições a serviço

* Este texto é uma versão ampliada da exposição da autora no simpósio Anísio Teixeira e sua Projeção Educacional além do Século XXI, durante a $52^{\mathrm{a}}$ Reunião Anual da SBPC, realizada de 9 a 14 de julho de 2000, no campus da Universidade de Brasília, DF.

** Pesquisadora associada ao Programa de Pós-Graduação em Educação da Universidade Federal Fluminense. Professora do Curso de Mestrado em Educação da Universidade Estácio de Sá. E-mail: claricenunes@openlink.com.br 
da reinvenção da ciência, da cultura e da política, da própria sociedade brasileira. Lembrar Anísio Teixeira, no seu centenário de nascimento, é chamar a atenção para o fato de que os homens capazes de manter o desejo pela educação por toda uma vida, como ele o fez, apesar das rupturas que the foram impostas pelas conjunturas políticas de 1935 e 1964, são imprescindíveis e, hoje, cada vez mais raros. No dia 12 de juIho, se Anísio Teixeira estivesse vivo, completaria 100 anos. No entanto, vivo na nossa memória, o seu devotamento incondicional à democracia e à educação para a democracia, traduzido em livros, artigos, relatórios, cartas e, sobretudo, em uma excepcional obra de administração pública, ainda se manifesta à frente do nosso tempo.

Quem foi esse homem? O que o motivou? Quem foi o seu grande educador? Que lições aprendemos com o inventário da sua obra? Como se expressa o vigor e a atualidade do seu pensamento para pensar a educação brasileira na atualidade? Essas são as questões que me mobilizam e se apresentam como um convite à reflexão de todos nós.

\section{Vida e obra de Anísio Teixeira}

Anísio Spínola Teixeira nasceu em Caetité, sertão da Bahia, em 12 de julho de 1900, filho de Anna Spínola Teixeira e Deocleciano Pires Teixeira. Após sólida formação adquirida no Instituto São Luiz Gonzaga, em Caetité, e no Colégio Antonio Vieira, em Salvador, ambos colégios católicos jesuítas, bacharelou-se em Direito pela Faculdade de Direito da Universidade do Rio de Janeiro, em 1922, e obteve o título de Master of Arts pelo Teachers College da Columbia University, em 1929. Casouse, em 1932, com Emília Telles Ferreira, com quem teve quatro filhos. Faleceu na cidade do Rio de Janeiro, em 1971 (Clarice Nunes, in Fávero e Britto 1999, pp. 51-5).

Anísio Teixeira iniciou-se na vida pública em 1924, quando recebeu o convite do governador da Bahia, Francisco Marques de Góes Calmon, para ocupar o cargo de Inspetor Geral de Ensino. Teve, nessa ocasião, a oportunidade de realizar a reforma da instrução pública nesse estado, durante os anos de 1924 a 1929. Nesse período, realiza uma viagem à Europa (1925) e duas viagens aos Estados Unidos (uma em 1927 e outra em meados do ano de 1928). Em ambas tem a chance de observar diversos sistemas escolares. Nos Estados Unidos trava contato com a obra do filósofo americano John Dewey que marcou decisivamente sua trajetória intelectual. Ao demitir- 
se deste cargo, por incompatibilizar-se com a proposta de governo do sucessor de Calmon, Vital Henrique Batista Soares, empossado em 1928, é nomeado como docente da Escola Normal de Salvador para lecionar Filosofia e História da Educação. Desse período data a publicação de Aspectos americanos da educação (1928) que, além das observações de viagem, traz o primeiro estudo sistematizado das idéias de John Dewey.

Em 1930, Anísio Teixeira publica a primeira tradução de dois ensaios de John Dewey que, reunidos, recebem o nome de Vida e educação. Após a morte de seu pai e de uma tentativa frustrada de eleger-se deputado federal pela Bahia, parte para o Rio de Janeiro onde, em 1931, assume, a convite do prefeito Pedro Ernesto Batista, a Diretoria da Instrução Pública do Distrito Federal. Nesse cargo teve a oportunidade de conduzir importante reforma da instrução pública que o projetou nacionalmente e que atingiu desde a escola primária, à escola secundária e ao ensino de adultos, culminando com a criação de uma universidade municipal, a Universidade do Distrito Federal. Demitiu-se em 1935, diante de pressões políticas que inviabilizaram sua permanência no cargo, em uma conjuntura em que o pensamento autoritário ganhava força no Estado e na sociedade.

Nesse período tornou-se um dos signatários do Manifesto dos Pioneiros da Educação Nova (1932), que divulgava as diretrizes de um programa de reconstrução educacional para o país. Também teve participação ativa na Associação Brasileira de Educação ( $A B E$ ), tendo publicado Educação progressiva - Uma introdução à filosofia da educação (1932) e Em marcha para a democracia (1934). Já estava afastado da vida pública quando editou Educação para a democracia: Introdução à administração escolar (1936).

Entre 1937 e 1945, Anísio Teixeira permanece na Bahia e se dedica à exploração e exportação de manganês, calcário e cimento, à comercialização de automóveis e à tradução de livros para a Companhia Editora Nacional. Em 1946, recebe o convite de Julien Sorell Huxley, primeiro-secretário executivo da Unesco, para assumir o cargo de Conselheiro de Ensino Superior, o que aceita apenas por um período de experiência, tendo recusado sua inserção definitiva no staff desse órgão, dentre vários motivos, pelo convite que recebeu de Otávio Mangabeira, governador da Bahia, para ocupar a Secretaria de Educação e Saúde desse estado, posto no qual permanece até o início da década de 1950.

Uma das mais importantes iniciativas de Anísio Teixeira na condução dessa pasta foi a construção do Centro Popular de Educação Carneiro 
Ribeiro, popularmente denominado de Escola-Parque, no bairro da Liberdade. A Escola-Parque, inaugurada em 1950, procurava fornecer à criança uma educação integral, cuidando de sua alimentação, higiene, socialização e preparação para o trabalho e a cidadania. Esta obra projetou-o internacionalmente.

Já no ano de 1951, Anísio assumiu, no Rio de Janeiro, a convite do ministro da Educação Ernesto Simões Filho, a Secretaria Geral da Campanha de Aperfeiçoamento de Pessoal de Nível Superior (CAPES), que seria, por ele, transformada em órgão. Já no ano seguinte, substituindo Murilo Braga, assumiu também o cargo de diretor do Instituto Nacional de Estudos Pedagógicos (INEP), no qual permaneceu até 1964.

Como Diretor do INEP, Anísio Teixeira criou o Centro Brasileiro de Pesquisas Educacionais (CBPE) com o intuito de coordenar estudos sociológicos, antropológicos, estatísticos e históricos sobre a realidade brasileira. Além dele, foram criados os Centros Regionais de Pesquisas Educacionais em Belo Horizonte, Recife, Salvador, São Paulo e Porto Alegre que realizavam diversos trabalhos articulados com as universidades dessas cidades e com a Secretaria de Educação e Saúde do Estado, no caso específico de Salvador.

Durante sua gestão na CAPES e no INEP, Anísio Teixeira proferiu inúmeras conferências pelo país e participou ativamente da discussão da Lei de Diretrizes e Bases da Educação Nacional (1961). Nesses anos de árdua luta pela escola pública, edita dois livros: $A$ educação e a crise brasileira (1956) e Educação não é privilégio (1957). Suas posições the valeram a perseguição dos bispos brasileiros que, em 1958, lançam um memorial acusando-o de extremista e solicitando ao governo federal sua demissão. Este episódio gerou o protesto de 529 educadores, cientistas e professores de todo o país que, em um abaixo-assinado, com ele se solidarizaram. Foi mantido no cargo por Juscelino Kubitschek, então Presidente da República.

Em 1961, foi um dos principais idealizadores da Universidade de Brasília (UnB) da qual assumiu a reitoria, em 1962, quando seu reitor Darcy Ribeiro precisou se afastar para assumir a chefia do Gabinete Civil da Presidência da República. Com a instauração do governo militar, em 1964, Anísio Teixeira foi afastado do seu posto e aposentado compulsoriamente. Embarcou para os Estados Unidos e lecionou como visiting scholar na Columbia University (1964), na New York University (1965) e a University of California (1966). Ao retornar ao Brasil, Anísio Teixeira conti- 
nuou a dedicar-se à educação. Permaneceu integrando o Conselho Federal de Educação até o final do seu mandato. Organizou reedições de antigos trabalhos, como Pequena introdução à filosofia da educação (1967); Educação é um direito (1967); Educação no Brasil (1969) e Educação e o mundo moderno (1969). Tornou-se consultor da Fundação Getúlio Vargas e voltou a trabalhar na Companhia Editora Nacional.

No início de 1971, aceitou candidatar-se à Academia Brasileira de Letras, mas a morte trágica interrompeu a sua trajetória. Em edição póstuma foi publicado seu livro Ensino superior no Brasil: análise e interpretação de sua evolução até 1969. Nos anos 90, sua obra começou a ser reeditada pela Editora da Universidade Federal do Rio de Janeiro, com o apoio da CAPES e da Fundação Anísio Teixeira. Este educador deixou ainda uma vasta produção distribuída em periódicos de circulação nacional e internacional, discursos, folhetos, prefácios, posfácios, instrumentos normativos (leis e planos), trabalhos apresentados em congressos e traduções.

O que torna a trajetória de Anísio Teixeira admirável é a persistência na defesa da democracia e da educação para a democracia, que constituiu o motivo central de devotamento da sua vida. Essa defesa não é apenas apaixonada. É polida por uma filosofia da educação e uma compreensão aguda da história da sociedade brasileira. É iluminada, como dizia Florestan Fernandes, pela sua imaginação pedagógica (Florestan Fernandes, in Lima Rocha, org., 1992, p. 46).

Anísio Teixeira fez parte de uma geração de intelectuais cuja preocupação maior, na primeira metade do século XX, foi organizar a nação e forjar o povo através de uma cultura que procurava assegurar a sua unidade pela instrução pública, pela reforma do ensino e pela construção de um campo cultural a partir da universidade. Essa preocupação levouo, como outros educadores que Ihe foram contemporâneos, a uma relação contraditória com o Estado.

Na década de 1920, ao afirmar sua opção pela educação, em oposição às carreiras religiosa e política, pelas quais também se sentiu atraído, Anísio Teixeira fez uma escolha em aberto, pois a carreira profissional de educador não estava ainda estruturada em nosso país. Ele iria trabaIhar, no decorrer da sua trajetória, para dotá-la de conteúdo e institucionalizá-la, levando para o novo campo que se constituía um amálgama de saberes e vivências das áreas religiosa, literária, política e jurídica, 
além da aquisição de uma filosofia de educação e de um programa de ação nos moldes do liberalismo de John Dewey.

A leitura de John Dewey, iniciada durante a década de 1920, proporcionou a Anísio Teixeira a possibilidade de construir um novo significado existencial, de encontrar resposta programática para as questões educacionais com as quais estava lidando e de elaborar uma síntese para uma nova visão de mundo. Sua apropriação de Dewey foi longa e múltipla e se desdobra em inúmeras publicações, traduções e na sua própria prática política. As suas experiências como docente e, sobretudo, como administrador, em diferentes conjunturas, foram depurando a sua escolha de temas e a sua apreciação sobre a obra deste autor. Se Dewey Ihe permitiu notável abertura para o mundo moderno, configurou-se também como o seu grande limite.

O liberalismo deweyano forneceu a Anísio Teixeira um guia teórico que combateu a improvisação e o autodidatismo, abriu a possibilidade de operacionalizar uma política e criar a pesquisa educacional no país. Anísio Teixeira não assimilou Dewey incondicionalmente. Ao contrário dele, que acreditava no pleno êxito das reformas educativas em países pouco desenvolvidos pela ausência de tradições culturais aí arraigadas, Anísio Teixeira conhecia e denunciou criticamente a força dessas tradições na sociedade brasileira. Ao contrário de Dewey, que em nenhum momento indicou, na sua vasta obra, quaisquer medidas de aferição de inteligência ou de escolaridade, Anísio Teixeira aplicou-as nas escolas da rede pública, na década de 1930. Se Dewey permaneceu como pensador independente, não se filiando a qualquer partido, para defender a reforma do governo municipal carioca, Anísio Teixeira chegou até a redigir um programa partidário. Se Dewey nunca entrou na polêmica entre escola confessional e escola pública, Anísio Teixeira mergulhou, em cheio, nela. Anísio Teixeira assumiu também a crítica deweyana dirigida tanto à escola tradicional quanto à escola nova, o respeito ao pluralismo e um pragmatismo temperado pela sua formação em colégios jesuítas e sua experiência na política regional.

Em quarenta anos de vida pública, Anísio Teixeira produziu inúmeros artigos, conferências e relatórios. Livros foram poucos e surgiram quase sempre nos intervalos de exercício de seus cargos públicos. Em toda a sua produção, o tema da democracia no âmbito da escola e fora dela foi decisivo e se impôs sobre outros temas. Sob essa ótica, elaborou uma interpretação de conjunto da história, da sociedade e da educação brasileiras ao buscar construir, sobretudo, uma ponte entre a reforma da socie- 
dade pela educação e a renovação cultural desejada, no sentido da valorização da ciência, do industrialismo e da democracia, que ganha com a sua vida e obra uma entonação própria, distinta mesmo de outros intelectuais que colaboraram com os seus projetos ou se opuseram a eles. Em síntese, o que Anísio Teixeira defende em tudo o que escreveu é a educação como um direito de todos. Uma análise das suas realizações pode ser ensaiada a partir de dois ângulos privilegiados para a apreensão da complexidade, sobretudo em sociedades como a nossa, de ser conseqüente com a afirmativa anterior: o ângulo da educação popular, relativa à formação de crianças, adolescentes e adultos e o da formação dos intelectuais.

Sob o ângulo da educação popular, Anísio Teixeira realizou, como secretário da Educação e Saúde, sobretudo no Rio de Janeiro, nos anos 30 , e em Salvador, nos anos 50, uma intervenção sobre a educação das classes populares no espaço da cidade. O caráter dessa intervenção é de capital importância para compreender a sua defesa da democracia, já que, ao lidar com a heterogeneidade, não o fez, como alguns de seus colaboradores e contemporâneos, de forma a identificá-la como decorrente da carência de atributos intrínsecos do sujeito pobre. Pelo contrário, Anísio Teixeira deslocou a carência do indivíduo para a omissão dos governos na direção da reconstrução das condições sociais e escolares, e isto fica patente nas medidas concretas que assumiu para alargar as chances educativas das crianças das classes populares e para dotar a escola pública de um ensino de qualidade.

Em uma espécie de voluntarismo calculado, construído pela crítica das condições escolares, pela crítica do privilégio das elites e pela autocrítica e crítica da sua gestão, Anísio Teixeira concebeu a escola como um espaço real no qual a criança do povo pudesse praticar uma vida melhor: livros, revistas, estudo, recreação, saúde, professores bem preparados, ciência, arte, clareza de percepção e crítica, tenacidade de propósitos. Tanto nos anos 30, no Rio de Janeiro, como nos anos 50, em Salvador, ainda que pesem as diferenças de região e de momento histórico, Anísio Teixeira preocupou-se com a elaboração de um plano de edificações escolares que permitisse não apenas a ampliação do número de matrículas, mas que também levasse em conta o projeto pedagógico voltado para o aluno na escola.

$\mathrm{Na}$ reforma do Distrito Federal, a ampliação do atendimento às crianças, a melhoria da sua freqüência e do seu rendimento, que incluía 
a cuidadosa preparação do professor e acompanhamento das suas atividades docentes, criaram um ambiente em que os agentes escolares cultivavam o sentimento da responsabilidade pela escola enquanto instituição pública. Do ponto de vista dos adolescentes, alunos das escolas técnicas secundárias, a heterogeneidade foi trabalhada dentro da concepção de uma política de ampliação das elites, o que significava também o aumento do número de matrículas e a defesa de que não bastava reunir disciplinas de cultura geral com práticas em oficinas, mas se exigia alargar o conteúdo de cultura geral, recolocando a prática de trabalho como complemento à prática da classe e do laboratório. Do ponto de vista da educação de adultos, ampliaram-se consideravelmente as oportunidades de freqüência aos cursos de extensão e aperfeiçoamento. Todas essas iniciativas sinalizaram uma posição corajosamente combativa no campo de lutas pela extensão dos serviços educativos, o que remetia, mesmo contraditoriamente, para um movimento de redistribuição dos bens sociais. Por que a contradição? Porque, ao mesmo tempo em que a gestão de Anísio Teixeira criava uma política de conjunto, centralizava os serviços educativos. Esta centralização reforçou a leitura da importância das iniciativas do Estado e, concretamente, facilitou o desmantelamento dos seus serviços com seu afastamento e o da sua equipe em 1935.

Já na sua atuação como secretário da Educação e Saúde, nos anos 50, na Bahia, concebeu a criação dos Centros de Educação Popular e implantou, no bairro operário da Liberdade, o Centro Educacional Carneiro Ribeiro ou, como ficou popularmente conhecido, a Escola-Parque. Nela, as práticas escolares estavam organizadas no setor de trabalho destinado às artes aplicadas, industriais e plásticas; no setor recreativo ou de educação física: jogos, recreação e ginástica; no setor artístico: teatro, música e dança; no setor de extensão cultural e biblioteca: leitura, estudo e pesquisa e no setor socializante: grêmio, jornal, radioescola, banco e loja.

A concepção que sustenta essas iniciativas é a compreensão de que o ensino primário como o secundário têm uma finalidade cultural e devem atingir idealmente todas as crianças até a idade de 18 anos. Dentro dessa perspectiva ampla é que, para Anísio Teixeira, se colocaria a preparação das elites em todas as atividades e classes e não apenas nas atividades intelectuais. Essa postura é que o leva à proposta de articulação do ensino secundário com o ensino primário e superior e à defesa de transferências razoáveis de alunos entre os vários ramos do ensino secundário existentes à época. Em suma, o que sempre defendeu na sua obra escrita e administrativa é a educação comum a todas as crianças pelo maior tempo possível, 
a ampliação de facilidades educativas para os alunos talentosos, a variedade e flexibilidade do sistema educativo para atender às diferenças de capacidade e interesses. Com relação a esse último aspecto, os cursos destinados aos adultos foram um sucesso, pois atendiam ao desejo e necessidade de aprimoramento de conhecimentos desses estudantes. Essas iniciativas constituem medidas concretas de redistribuição da educação como bem social. É nessa perspectiva que parece pertinente avaliar tanto o papel das modificações escolares que Anísio Teixeira introduziu nas reformas que conduziu quanto sua contribuição como intelectual.

Do ponto de vista da formação dos intelectuais, o projeto de Anísio Teixeira passa pela criação de instituições, universitárias ou não, que formulem intelectualmente a cultura humana, sejam capazes de incentivar (no caso de órgãos de fomento à pesquisa ou ao aperfeiçoamento docente) e funcionar (no caso das universidades ou dos centros de pesquisa) como pólos de irradiação científica, literária e filosófica, tenham a pesquisa como um valor e a vinculem à docência. A trajetória de Anísio Teixeira em defesa da universidade pública e de instituições públicas de pesquisa ou de financiamento a ela tem implícita a convicção de que não há país capaz de sobrevivência digna sem instituições, sobretudo como a universidade, capazes de produzir conhecimentos e propor soluções próprias às questões que 0 afligem.

A grande novidade na concepção da Universidade do Distrito Federal (UDF), criada em 1935, é que ela se apresentava como locus de aglutinação de professores. Pela primeira vez no país, através da Escola de Educação, que se situava ao lado dos Institutos de Filosofia e Letras, de Ciências, de Política e Direito, de Artes e Desenho e de Música, o magistério alcançava uma formação em nível superior. A concepção de que o profissional da educação é um intelectual e de que a Escola de Educação tem relevância no interior do projeto universitário justifica-a e evidencia o ponto alto de um processo que, já nos anos 20, levara a antiga Escola Normal do Rio de Janeiro a ser transformada em Instituto de Educação. O que está no cerne da concepção de universidade em Anísio Teixeira é a melhoria da qualificação docente, cuja prática via como um misto de ciência e arte e cujo papel reunia a investigação e a transmissão dos conhecimentos produzidos.

A UDF foi incorporada à Universidade do Brasil em 1939. Teve o seu projeto sufocado e substituído, pois este colidia com os propósitos do governo federal com relação à educação e ao ensino universitário. Esta 
colisão levou a uma triagem ideológica e doutrinária dos seus docentes em prejuízo dos ideais democráticos. Se, para Anísio Teixeira, a reconstrução do país se fazia pela disseminação da mentalidade científica e pelo estilo democrático de vida, para Gustavo Capanema, que expressa a posição do governo federal, a reconstrução do país se faria pelos valores nacionais. Importava que os valores nacionais fossem inculcados nas massas para facilitar o processo de aceitação da autoridade dos seus líderes.

Mesmo com uma duração efêmera, a UDF deixou seu legado às novas gerações. O seu legado é sua própria concepção, que enraizava a universidade à sociedade, entendia a ciência como crítica e autocrítica, construía o saber universitário no diálogo com diferentes campos de conhecimento e, dentro dessa forma de entender o ensino superior, ancorava a Escola de Educação articulada ao sistema educativo como um todo, locus de intersecção das ciências, da filosofia e da prática educativa, espaço de formação profissional da educação valorizado na sua dimensão intelectual. Expressa-se aí uma convicção simples de entender e difícil de praticar: não há possibilidade de aprimorar a educação em qualquer nível sem aprimorar a formação docente.

A Universidade de Brasília (UnB), criada nos anos 60, foi acalentada por uma comunidade científica que desejava mudar a estrutura universitária na sociedade brasileira. Ela já surgiu com cursos de pós-graduação ao lado de cursos de graduação. Possuía oito institutos centrais (Matemática, Física, Química, Biologia, Geociências, Ciências Humanas, Letras e Artes), cada um deles dividido em Departamentos para os quais foram recrutados jovens professores nas diversas regiões do país. O intercâmbio entre os institutos estava previsto, e vários cientistas e educadores se pronunciaram sobre o seu projeto. Foi concebida para tornar-se a melhor experiência educacional da América Latina e se propunha a gerar uma comunidade de pesquisadores capazes de diagnosticar e oferecer soluções aos problemas da realidade brasileira.

Anísio Teixeira tinha uma consciência aguda da dimensão pública da tarefa intelectual, tarefa que para ele só tem sentido se está a serviço de um projeto político-social a ser implantado e que leve em conta os oprimidos. Essa solidariedade era, na sua atuação, não apenas movida por um sentimento moral. Era também apoiada no fato de que ele se assumia como educador-dirigente sem perder (pelo contrário, reafirmando) os fundamentos mais elaborados da vertente do pensamento liberal que Ihe servia de plataforma de lançamento. 
Ao mesmo tempo em que participava da criação de diversas instituições e as conduzia no sentido de construir e preservar a educação pública de interesses espúrios, travava lutas ásperas no sentido que the parecia o mais correto: de aplicar preferencialmente fundos públicos, fossem eles federais, estaduais ou municipais, na educação das escolas públicas, o que não significava desrespeitar a iniciativa particular.

Sua habilidade de estrategista colocava os órgãos sob a sua condução, como o INEP, por exemplo, não só a produzir pesquisas que dessem suporte ao seu projeto, através do Centro Brasileiro de Pesquisas Educacionais e dos centros regionais articulados, por via de regra, às universidades locais, mas, sobretudo, a oferecer, através dos resultados dessas pesquisas, subsídios para um planejamento educacional que, na medida das possibilidades, era realizado, em alguns de seus aspectos, mediante convênio entre o INEP e as secretarias de educação estaduais. Estes convênios patrocinaram equipamentos para escolas primárias, construção de centros de aperfeiçoamento docente e cursos voltados para o objetivo de produzir um profissional atualizado e competente e, em última instância, contribuir para incentivar a ampliação da escolaridade primária nas escolas públicas e minimizar, sempre que possível, suas deficiências. Não é por acaso que, ao mesmo tempo em que criava o Centro Brasileiro de Pesquisa Educacional, capitalizava a luta pela escola primária e pelo controle da formação docente. É que, sendo os educadores especialistas em processos, em modos de pensar, ser-lhes-ia possível, através da generalização da instrução, transmitir os modos pelos quais a ciência chegava a certos resultados em seu exame sobre a realidade brasileira. A meta era a maioridade do povo brasileiro não só pela valorização da cultura popular, mas também pela sua transformação em instrumento efetivo de construção da sua autonomia.

Foi através do CBPE que Darcy Ribeiro passou a colaborar ativamente com Anísio Teixeira para o desenvolvimento de pesquisas científicas, o que exigiu a articulação de intelectuais brasileiros com pesquisadores estrangeiros e organismos internacionais. Dentre os projetos desenvolvidos, alguns foram patrocinados pela Unesco, que investiu recursos no desenvolvimento de pesquisas na área de ciências sociais. A educação tornou-se o objeto de pesquisa social central. Darcy Ribeiro chegou a formular um programa extremamente ambicioso, denominado Programa de Pesquisas em Cidades Laboratório, cuja proposta era captar as particularidades regionais do Brasil a partir do estudo de comunidades típicas. 
Mesmo que esse projeto não tenha sido realizado integralmente, o seu caráter inovador se expressou no fato de trabalhar com a hipótese de que as políticas implementadas no país endossavam a representação de um Brasil hipotético, homogêneo e uniforme e que, dadas as nossas diversidades culturais, os planos unificados (nacionais, únicos) não tinham sentido. Há aí todo um esforço não só para produzir conhecimentos, mas também para desconstruir as representações que a ditadura varguista havia consolidado entre nós (Xavier 2000, pp. 141-246).

A grande polêmica no diálogo entre cientistas e educadores, dentro do Centro Brasileiro de Pesquisas Educacionais e dos centros regionais, centrou-se em torno de duas questões: a paradoxal relação entre ciência e política e a hierarquização que gradativamente se estabeleceu entre ciência pura e ciência aplicada, o que ocasionou momentos difíceis entre os educadores, interessados na urgente aplicação dos conhecimentos produzidos dentro das escolas, e os cientistas sociais, que ora se afastavam da educação escolar, propondo temas mais amplos a partir da substituição do conceito de educação pelo de socialização, ora apresentavam propostas de estudos mais teóricos e desinteressados, protegendose assim de interferências e demandas externas ao seu trabalho (idem, ibidem).

A criação do CBPE e dos centros regionais, assim como a política do INEP, acabaram provocando polêmica e resistência dos setores reacionários dentro e fora do Ministério da Educação. Por ocasião do debate em torno da Lei de Diretrizes e Bases da Educação (1961), Anísio Teixeira foi obrigado a defender-se dos ataques recebidos, afirmando os princípios que orientavam sua vida de educador e disciplinavam sua atividade nos órgãos públicos pelos quais passava e que eram os seguintes:

Era contra: a educação como processo exclusivo de formação de uma elite; o analfabetismo; a ausência, a evasão e a repetência da criança na escola; a falta de consciência pública para situação tão grave; a desvinculação do ensino médio das exigências da sociedade moderna; a seletividade extrema no ingresso às universidades; o esvaziamento do ensino superior e a dispersão de esforços pela multiplicidade, nesse nível de ensino, de escolas improvisadas ao invés da expansão e fortalecimento das boas escolas.

Era a favor: de uma escola primária organizada e séria, com seis anos de estudo nas áreas urbanas e quatro na zona rural, destinada à 
formação básica e comum do povo brasileiro; de uma escola média em que a língua, a civilização nacional e a ciência fossem os verdadeiros instrumentos de cultura do aluno; à aplicação dos recursos públicos assegurados pela Constituição à educação à luz de dois critérios básicos: assegurar a cada brasileiro o mínimo fundamental da educação gratuita e de somente custear com recursos públicos a educação pós-primária de alunos escolhidos em competição por esforço e inteligência. Declarava-se, enfim, a favor de uma educação voltada para o desenvolvimento, que realmente habilitasse a juventude brasileira à tomada de consciência do processo de autonomia nacional.

Este pensador liberal foi acusado de comunista em vários momentos de sua vida pública, sobretudo pelos setores mais conservadores da Igreja Católica. No entanto, como afirmava, jamais leu Marx. Era capaz, no entanto, de dialogar com a multiplicidade de posturas presentes nas equipes que reunia. Ao procurar observar o movimento de Anísio Teixeira em suas respostas aos desafios colocados pela prática política, podese notar que ele age, dependendo das situações, segundo lógicas diferentes, o que muitas vezes confunde seus interlocutores e comentaristas que ficam surpresos ou chocados com sua incoerência. Sem dúvida ele parece assumir o estilo jesuítico quando, por exemplo, luta obstinadamente para alterar as rotinas da escola pública, procura controlar e medir as atividades escolares (anos 30), realiza um trabalho de demonstração e organiza operacionalmente a luta pela defesa de sua obra (anos 30, 50 e 60). No entanto, também utiliza a argúcia do político na influência que exerce, em diversas circunstâncias, entre os grupos dirigentes, ou ainda quando faz certas concessões na indicação de nomes para ocupar certos cargos, sem nunca esquecer, no entanto, os interesses da proposta educativa que conduz. Ainda, encarna o pensador liberal quando define os princípios de seu projeto educativo, quando ativa a teoria para criar as condições de gestão e os objetos que surgem do trabalho aí desenvolvido.

Essas possibilidades entrevistas apontam para a equívoca tarefa de enquadrá-lo em qualquer esquema classificatório. Essa incoerência que alguns apontam em Anísio Teixeira é coerente com sua biografia e o mistério das relações humanas sempre presente nas situações do cotidiano. De qualquer forma, a atenção ao esforço de Anísio Teixeira e à sua obra sempre ilumina a complexa batalha pela democratização da cultura e da educação, tornando-o um dos educadores que mais encarna nossa tradição pedagógica democratizante, tradição essa que exige a 
liberação dos preconceitos produzidos pelo temor à autoridade, pelo pensamento apressado, além da arte da palavra como instrumento de argumentação. Um intelectual sem arrogância, sem medo e sem preguiça, talvez Anísio Teixeira possa ser identificado, como o fez afetuosamente Jorge Amado, quando Ihe dedicou seu romance Capitães da areia, simplesmente como "o amigo das crianças"!

\section{John Dewey: 0 educador do educador}

A vida e as concepções de educação de Anísio Teixeira sofreram influência decisiva do pensamento de John Dewey (1859-1952) justamente entre meados de 1928 a meados de 1929, quando ele passou dez meses no Teachers College, da Universidade de Colúmbia, em Nova lorque, com uma bolsa no valor de 1.800 dólares, patrocinada pelo Macy Student Fund do International Institute.

A compreensão dessa influência é importante não só para entender os pontos de convergência e afastamento do educador brasileiro com relação a essa matriz filosófica, mas também para lançar luz sobre certas interpretações equivocadas, porque reducionistas, das direções da reflexão de ambos. A apropriação de Dewey por Anísio foi longa e múltipla. Abarca um período muito maior do que vou focalizar e se desdobra nas suas publicações, traduções e na sua própria prática na gestão da escola pública no país. O contato de Anísio com a obra de Dewey ocorreu na sua segunda estadia nos Estados Unidos. Ele já não era mais o deslumbrado da primeira visita. Conseguia ver, como confidenciou a Lourenço Filho, em 1935, a América por dentro (Arquivo Lourenço Filho, LF 59.00.00/1).

Dentre suas anotações escritas na Universidade de Colúmbia, encontrei, em uma lista de livros selecionados para serem lidos, Impressions of Soviet Russia (1929) (Arquivo Anísio Teixeira, Notas de aulas, AT 27.01.06 t). Este livro, que acabava de ser publicado, apresentava uma série de artigos nos quais Dewey relatava suas impressões da visita que realizara à União Soviética em 1928. Durante essa estadia, Dewey observou o que se passava nas escolas soviéticas e na difusão da cultura pela massa. Ele ficara impressionado, bem impressionado apesar da predominância da propaganda do governo nas escolas. A visão que Dewey divulga das realizações escolares soviéticas Ihe renderam acusações de "vermelho" e "bolchevista". Essa boa impressão seria modificada já em 1939, quando publicou Freedom and culture. O importante nesse episódio é destacar 
que, nos anos 20, Dewey realizava diversas viagens pelo mundo, e nos seus relatos primava, como salienta Perry Anderson, pelo respeito aos povos russo, turco, chinês, mexicano, escrevendo sobre eles com simpatia e aproveitando para criticar o imperialismo britânico, chinês e norte-americano. Em 1937, ele presidiu o comitê internacional que investigou o caso Trotsky e denunciou corajosamente a farsa dos julgamentos de Moscou (Anderson 1989, p. 26). John Dewey caracteriza-se, portanto, como intelectual engajado. Embora não pertencesse a nenhum partido político, pronunciava-se abertamente, denunciando o que considerava não ético do ponto de vista político. Na sua trajetória, ele se decepcionou tanto com o Partido Democrático quanto com os socialistas, julgando ambos incapazes de realizar uma mudança política radical. Preferiu alistar-se, nos anos 30, na League for Independent Political Action, que não era um partido nem pretendia sê-lo.

Quando Anísio começa a ler Dewey, os Estados Unidos estavam passando por um amplo debate em relação à política de imigração, graças a uma lei de 1921 que endossava a restrição étnica dos eslavos-latinos dentro da população norte-americana. O mosaico racial em que se transformava esse país era avaliado pelos norte-americanos como uma catástrofe. O critério de seleção individual e do valor pessoal proveniente do antigo liberalismo herdado da Inglaterra era substituído pelo critério étnico e racial e, em nome desse critério, os direitos do corpo social vinham sendo limitados, cada vez mais, em termos de manifestações de liberdade sindical e individual. A resposta para essa situação era a reorganização do sistema escolar. Por esse motivo, nesse momento, a grande discussão pedagógica era o currículo, que se tornava alvo da investigação e intervenção dos mais diversos pensadores: sociólogos, cientistas políticos, estudiosos das relações internacionais, da imigração e da opinião pública. No debate que se espalhava e crescia, Dewey era um crítico contundente dos impasses da democracia norte-americana. Já havia colaborado diretamente com instituições instaladas no meio da população pobre e imigrante com objetivos filantrópicos e educativos. Mostrava que a ameaça à democracia norte-americana não estava propriamente fora do país, mas dentro dele, nas atitudes pessoais e nas instituições.

O crescimento da rede escolar e os problemas práticos que colocava levaram Dewey a escrever expressamente para os educadores. Em 1910, ele já havia publicado How we think, no qual procurava relacionar pensamento reflexivo ao processo educativo, mostrando que ao professor 
cabia ensinar mais e melhor e ao aluno cabia a iniciativa de aprender. Nesse livro, ele defende o pensamento experimental, mas o relativiza na medida em que coloca o controle da atividade reflexiva na própria situação experienciada pelo professor, o que significa que, a rigor, não há receita para essas vivências reflexivas. Elas são obra de contágio, do exercício do rigor e da imaginação, da atividade lúdica que não degenera em folia e do trabalho que não degenera em castigo.

Quando Anísio assume Dewey como seu pensador preferido, este já era um conceituado professor universitário, com uma carreira que passava pelas Universidades de Vermont, John Hopkins, Michigan, Chicago e Colúmbia, com uma vasta obra sobre temas de filosofia, ética, psicologia, política, sociedade e educação. Já havia participado diretamente de experiências pedagógicas, como a escola elementar ligada à Universidade de Chicago, que só Ihe deu problemas financeiros, e a Hull House, instituição que acolhia imigrantes, criada em 1899 e dirigida por Jane Addams, sob a concepção da interdependência entre as classes sociais.

Do ponto de vista psicológico, Dewey foi uma resposta a Anísio, no momento em que seus velhos valores e seguranças, inspirados na religião católica e abraçados com arrebatamento, ruíram. Foi também a possibilidade de unificação entre o sentimento e o intelecto, entre o sagrado e o secular, que o catolicismo nunca Ihe proporcionara. Arrisco a afirmar que Dewey foi para Anísio o que Hegel foi para ele. A síntese hegeliana entre o sujeito e o objeto, matéria e espírito e divino e humano operou em Dewey um profundo sentimento de liberação das divisões por ele herdadas da cultura da Nova Inglaterra e que isolavam o seu eu do mundo, sua alma do corpo, a natureza de Deus e que Ihe causavam doloroso dilaceramento interno. Se Dewey recusou em Hegel o caráter metafísico da formulação da atividade de pensamento, tomando-a em sua condição empírica, manteve-o no seu estilo de escrita que combina estrategicamente concepções contrastantes segundo determinados conceitos mediadores e, de certa forma, manteveo também na atitude que Umberto Eco vislumbrou, de que a sua análise inspirada na ciência culmina em um momento de comoção diante do cosmo (Eco 1971, p. 70). Essa emoção Dewey não trabalha no nível da reflexão, embora em 1934 ele tenha publicado $A$ common faith, livro que Anísio recebeu de presente de Lourenço Filho em 1935.

Esse livro é muito interessante. Dewey diz, nessa publicação, que a crise religiosa não existe, o que existe é crise teológica, crise da Igreja, da política clerical. Ele redimensiona a idéia de divino como a união ativa 
entre o ideal e o real. Salienta que os ideais que nos dirigem são gerados pela imaginação e, à medida que são colocados em prática, se transformam. Essa união dos ideais com as condições reais é capaz de despertar emoções estáveis, melhores quando associadas à inteligência. Se os homens e mulheres agissem o tempo todo e em toda a amplitude das suas relações humanas com a fé e o ardor que tinham constituído a história da religião, os resultados seriam, segundo ele, imprevisíveis. Nesse mesmo texto, Dewey critica tanto o ateísmo agressivo como o sobrenaturalismo tradicional. Critica o cristianismo histórico pelo seu empenho em separar os bons dos maus, passando por cima da fraternidade comum entre todos os homens. Para Dewey, todos nós participamos de uma comunidade de causas e conseqüências, símbolo profundo da totalidade misteriosa que a imaginação denomina universo. É essa participação que nos liga às gerações que nos antecederam e à que nos sucederá. E com esta última temos a responsabilidade de conservar, transmitir, retificar e expandir a herança dos valores recebidos de uma maneira mais sólida, generosa e amplamente acessível. A fé compartilhada de Dewey é a expressão de um "naturalismo" que não significa um entusiasmo geral pela ciência contra a religião. Pelo contrário, Dewey recoloca a discussão moral e a emoção religiosa sob uma base secular. Graças à sua concepção evolutiva, ele não só distinguiu os homens dos outros tipos de animais, mas fez dos objetivos morais o cerne dessa distinção, localizando a ética na dimensão humana e separando o ético do cósmico.

O pensamento deweyano funcionou para Anísio como um regaço materno no qual pôde relaxar suas crenças anteriores, trabalhando sobre elas. Representou a mediação entre o estoque de velhas opiniões e a nova experiência vivida, amaciando o seu período de transição graças à maleabilidade da sua teoria e à plasticidade que atribuía à verdade, avaliada sempre pela conseqüência prática das idéias. Mais do que uma resposta à coerção que durante tanto tempo sofrera na batalha da ordem sensível contra a ordem ideal, Dewey significou para ele um instrumento que the permitiu alargar o seu campo à procura de Deus. Seu compromisso com a verdade ganhou uma espécie de mobilidade alimentada por uma atitude de reserva, para a qual qualquer idéia seria verdadeira se a crença nela fosse proveitosa para a sua vida e para a dos outros. Nesse sentido, passou a admitir que a verdade é construída e se estabelece à custa de um sistema de crédito posto à prova quando algo o desafia. Seu movimento de ler e traduzir Dewey pode ser compreendido como um modo de conhecê-lo e, ao mesmo tempo, não só permitir que novas idéias enxertassem 
antigas verdades, estendendo-as o suficiente para fazê-lo admitir a novidade, mas também de reconstruir sua identidade com o máximo de continuidade possível. Dewey permitiu a Anísio manter sua fé religiosa, mesmo abraçando a Ciência e criticando a Igreja enquanto instituição histórica e organização política. Dewey reforçou, nele, a intuição da possibilidade da aliança entre o político e o místico, entendendo-se por místico não mais o enlevo sobrenatural, mas o movimento de jogar sua inteligência e sentimento na conversão do seu pensamento em ação e da sua imaginação em experiência social.

Anísio fez do naturalismo de Dewey uma ponte entre o "pragmatismo" jesuítico e o pragmatismo liberal. Essa ponte foi construída pela concepção de homem como uma criatura de hábitos e pela importância que assume, para jesuítas e liberais, a força das personalidades. A concepção de hábito é uma das três concepções-chave da psicologia deweyana, ao lado do impulso do intelecto. A força da personalidade, como indica Horowitz em sua introdução à obra de Mills, é o eixo de uma filosofia que começa com a experiência pessoal, em oposição a outras concepções cujo ponto de partida é a existência objetiva (Mills 1966, p. 26).

A concepção do homem como criatura de hábitos parte de uma reelaboração do modelo darwinista assumido por Spencer. Em Dewey, a natureza biológica humana é plástica o suficiente para modificar os instintos e unitária o suficiente para abrigar um conjunto de certos valores. A conseqüência dessa reelaboração é a negação da rigidez dos instintos e a crença na necessidade de a sociedade trabalhar a natureza humana para que ela, implicitamente boa, cresça e seja desenvolvida em sua sociabilidade. Nessa sociabilidade reside algo da racionalidade e da bondade humanas. Dessa forma, Dewey evita não só o determinismo moral e social do homem, mas também glorifica romanticamente a individualidade, já que a sujeição aos instintos não é, para ele, uma manifestação de liberdade. Uma conseqüência importante dessa concepção é, de um lado, a crença de que as reformas sociais são possíveis e de que a educação tem um papel decisivo a desempenhar nessa direção, pois compete a ela modificar hábitos adquiridos e provocar historicamente a mudança de costumes. Desta posição, Dewey evita a inércia dos conservadores presos à força dos hábitos hereditários e a pressa dos revolucionários em suas estratégias específicas de mudança social.

Existe uma aproximação entre esse ponto de vista e aquele presente no ideal da Companhia de Jesus. Para ela, o homem-Deus é o exemplo 
acabado da mais alta perfeição humana. Não é instinto, nem razão. É o instinto modificado pela razão, iluminada pela sabedoria divina. Compreende-se, portanto, a importância do ensino como meio de regeneração da humanidade, a reforma das idéias como fundamental à melhoria dos costumes e à busca do equilíbrio no exercício das faculdades humanas. Nem inércia, nem pressa, mas o fortalecimento de uma vontade que domine as paixões inferiores e as sujeite à razão ancorada na fé. Aí reside a força de uma personalidade virtuosa, que se impõe à admiração e ao entusiasmo dos que a cercam, mas... que, ao mesmo tempo, tem receio de libertar aspectos inexplorados da sua própria maneira de ser e foge dos prazeres da vida. Por que tanto sacrifício? Por que bloquear o crescimento do sujeito para novas e mais ricas experiências? As respostas a estas perguntas a pedagogia jesuítica não dava a Anísio.

Dewey também fundamenta as respostas programáticas de Anísio Teixeira para as questões educacionais com as quais estava lidando. A concepção deweyana de democracia e mudança social está centrada na criança. Nessa perspectiva, o enraizamento e as direções que essa mudança assume estão postas na infância. Daí a importância da função social da educação e de seu caráter democrático, entendida como o processo pelo qual os indivíduos desenvolvem um interesse pessoal nas relações sociais, na sua direção e na formação de hábitos que permitam mudanças sem que estas ocasionem desordens.

No livro Democracy and education (1916), lançado no Brasil em 1936 com prefácio de Anísio Teixeira, Dewey apresenta sua concepção de democracia e os meios de realizá-la. Após examinar as filosofias típicas da história da educação (platônica, racionalista e idealista), mostra o seu reducionismo do ponto de vista dos objetivos educacionais, por excluírem o desenvolvimento natural da criança e a eficiência da sociedade e da cultura sobre esse desenvolvimento. É sob esse ponto de referência que ele trabalha a correlação entre interesse e disciplina, experiência e pensamento, pensamento e educação, e chega ao miolo do trabalho escolar examinando problemas metodológicos, curriculares, epistemológicos e morais.

Já na apresentação que Anísio Teixeira faz da obra, ele chama a atenção para o caráter conciliatório e sintético do pensamento deweyano: "nem restauração do passado nem imposição de um futuro ainda inexistente", mas ação prudente, que não é bruta (e, portanto, cega e ininteligente), nem repetição (e, portanto, preguiça). É uma ação, como afirma 
Anísio, que revigora o que o passado tem de útil e operante e readapta o que houve de novo e eficaz.

A concepção de democracia parte de um aspecto central no conjunto da obra deweyana: a análise de como se pensa. A ênfase na particularidade empírica do pensamento é relacionada com os conceitos de situação problemática e de ação. Ambos têm a função de localizar o pensamento na prática e delimitá-lo no domínio do homem na natureza. Essa postura eleva o comportamento humano, como salienta Mills, a um status de respeitabilidade filosófica jamais alcançado dentro do pragmatismo, pelos seguintes motivos: Dewey inclui o epistemológico e o mental no pensamento e apresenta a ação num contexto ético. Desse ponto de vista, afasta-se de outros pragmatistas, como Peirce, cuja compreensão da ação, embora ligada à mentalidade, é restrita às atividades de laboratório, e James, que generaliza sua noção em determinada direção moral (idem, pp. 364-5).

As fontes do modelo deweyano de comportamento e ação foram extraídas dos interesses que desenvolveu em Vermont e John Hopkins. São duas: uma psicologia do comportamento orientada biologicamente e certos procedimentos da ciência física e experimental. Pela primeira vez ele "naturaliza" a mente e delineia o pensamento como função biológica capaz de adaptar o homem ao meio. Adaptar não é conformar. Há uma plasticidade dos instintos (e, por extensão, do organismo) na sua concepção que não pode ser esquecida. Ao assumir a hipótese darwinista e aplicála ao social, Dewey comete o equívoco de estabelecer uma continuidade entre o nível biológico e lógico. Procura também uma abertura na concepção de ajustamento que a formaliza e, ao mesmo tempo, a indefine, por diluir a perspectiva da fragmentação e do poder das divisões sociais. Essa diluição contribui não só para localizar na inteligência a resolução dos problemas humanos, mas também para defender a educação no sentido de difundila, além de implementar uma política reformista das situações.

Da ação ele retira o paradigma da investigação. Coloca a autoridade intelectual no experimento e faz uma generalização do inquérito científico dos laboratórios para o inquérito social, atribuindo-lhe usos políticos ao combinar métodos científicos e valores morais. Para Mills, Dewey utiliza de uma maneira ambivalente a concepção do caráter social da ciência. É social no sentido do inquérito coordenado e pública quanto aos seus métodos e resultados, e também é social no sentido de bem-estar. Essas concepções distintas são borradas em contextos decisivos, e a ciência (e a tecnologia) aparece como reação contra o individualismo egoísta e pecuniário. Essa 
significação religioso-social da ciência teve, no entanto, uma razão histórica: até a Primeira Guerra Mundial, o seu prestígio era grande em diferentes níveis de público e praticamente todos obtinham algum retorno com o seu avanço e crescimento, independentemente do caráter diferenciado desse retorno. A guerra vai abalar esse sucesso. Poderia essa distribuição diferencial ser contra os interesses sociais? O método científico falhara?

A polêmica em torno do papel da ciência só ganhará contorno mais nítido nas obras escritas por Dewey no final da década de 1930. O importante a ressaltar é que ele levou aos educadores a mensagem de que a teoria social é um guia metodológico de investigação e planejamento. $\mathrm{O}$ sentido político dessa prática é a concepção de múltiplos e simultâneos movimentos de reforma. Isto é, para organizar o público é preciso, primeiro, descobri-lo. Esse problema é primariamente intelectual. Diante de estruturas e situações específicas em interação, o que se exige são inquéritos específicos que permitam direcionar e compactar a força da ação sobre alvoschave dentro de certa estrutura. Daí a importância de ganhar certa compreensão dos problemas como eles aparecem e de enfatizar a comunicação dos resultados revelados pela pesquisa, o que funciona como formação de uma opinião pública e reforça a ligação entre democracia e pensamento racional. Na raiz da concepção de teoria social está ancorado também o desejo de "salvar" e construir a individualidade. Nesse sentido, como uma linha transversal, a concepção política do liberalismo de Dewey cruza a reflexão psicológica, base de todos os seus escritos educacionais, e se distingue tanto do determinismo biológico quanto do individualismo do laissez-faire.

Dentro dessa ampla perspectiva é que Dewey apresenta, em Democracy and education, os aspectos vocacionais. Para ele, vocação significa atividade contínua que produz serviço para o outro e empenha as aptidões pessoais em benefício da obtenção de certos resultados. Se ele critica a oposição, na educação, ao reconhecimento dos aspectos vocacionais da vida, que acompanhariam a conservação dos ideais aristocráticos, insurge-se também contra a preparação profissional rigidamente adaptada ao regime industrial existente, por dar às massas uma limitada e prática educação técnica para profissões especializadas, exercidas sob a direção de terceiros. Essa concepção de educação vocacional significaria a perpetuação da antiga divisão social, com seu respectivo dualismo intelectual e moral, e não se justificaria, inclusive, pela dependência cada vez maior das ciências no trabalho industrial e pelo modo como Dewey as concebe, 
isto é, o estudo das ciências teria um papel fundamental no desenvolvimento do caráter e do espírito. A educação vocacional deveria, em sua concepção, dar aos que dispõem de menos oportunidades econômicas o desejo e as condições para participar da direção social e a aptidão de se tornarem senhores do seu destino na indústria.

A realização vocacional encontra em Dewey sua resolução na defesa de um sistema público de educação que permita a todos usufruírem dos benefícios da igualdade no aparelhamento para futuras carreiras. Essa proposta o afasta da perspectiva estreita tanto da educação confessional quanto de certas "seitas" escolanovistas. Afasta-o também, e muito, daquela imagem cristalizada que os comentaristas apresentam: a de idealizador de uma escola vocacional para a classe trabalhadora, entendida como preparação profissional direcionada para os interesses da indústria.

Do ponto de vista epistemológico, Dewey permitiu a Anísio elaborar uma síntese própria cuja chave é a categoria de reconstrução, forjada no âmbito da crítica filosófica elaborada pelo primeiro, e que introduziu Anísio no pensamento moderno do qual a escolástica o mantivera afastado na adolescência e parte da juventude. Reconstruction in philosophy (1920) só foi traduzido no Brasil na década de 1950, por Eugênio Marcondes Rocha e Jacob Thealdi, sob a supervisão e correção de Anísio. Escrita após a Primeira Guerra Mundial, já trazia as marcas do choque que Dewey sofrera e que balançara seu otimismo precedente, baseado na crença de um ininterrupto progresso na compreensão mútua entre classes e povos. Ele propunha uma revisão crítica do passado e a reconstrução da teoria do conhecimento com o propósito de verificar onde e como falhavam, em relação às condições modernas de vida, os sistemas filosóficos do passado. Essa reconstrução da teoria do conhecimento era necessária à reconstrução da filosofia para que esta repensasse a ciência, o que Ihe exigiu esforços contínuos no sentido de também reconstruir as concepções morais e religiosas, a cultura, a educação e a democracia.

Essa categoria de reconstrução permitiu a Anísio interpretar a filosofia como um esforço contínuo de reconciliação e reajustamento entre a tradição e o conhecimento científico, entre as bases culturais do passado e o presente. Dewey permitia a Anísio reintegrar o velho e o novo por meio de uma crítica capaz de distinguir, selecionar, pôr em relevo aspectos fundamentais do momento histórico vivido. Dewey mostrava-lhe que o moderno carecia de forma. Era embrionário. Ainda não existia. Seria o produto de uma decidida e paciente atividade conjunta de homens e mulheres de boa vontade, pro- 
vindos de todas as profissões e dedicados a essa tarefa por um tempo indefinidamente longo. Seria necessária uma nova erudição capaz de abarcar tanto a história da cultura quanto a ciência moderna. O que fascinava Anísio era a denúncia deweyana de uma tradição filosófica autoritária. Era justamente a recuperação do sentido humano que ganhava a história da filosofia e que se desdobrava na compreensão de que o papel de qualquer filosofia futura seria não só clarear as idéias dos homens quanto aos embates sociais e morais de seus próprios dias, mas também de ajudá-los a tomar posição dentro desses conflitos de modo a respeitar as aspirações humanas. A ciência moderna não havia trazido alívio à situação do homem. Para ele esse alívio só viria se, além de manipular a natureza, o homem produzisse novos ideais e agisse de modo sistemático para realizá-los. Nessa ação não poderia deixar de lado os meios.

Ao assinalar as tarefas de reconstrução da filosofia, Dewey dirigia sua crítica tanto ao idealismo germânico, quanto à escola individualista francesa e inglesa (séculos XVII e XIX) que, empírica na intenção, baseou seu individualismo na crença de que só o indivíduo era a única realidade, enquanto as classes e organizações eram coisas secundárias e derivadas.

A individualidade, num sentido moral e social, era para Dewey alguma coisa a ser forjada. As modificações sociais seriam os únicos meios de criação de novas personalidades. Daí a importância de analisar as instituições à luz dos seus efeitos educativos e não separar a política da moral. Por trás dessa postura existe a seguinte questão: qual o efeito que certas disposições sociais, políticas ou econômicas teriam sobre o caráter? Ao considerar o papel do Estado à luz dessa preocupação, Dewey criticava o dogma da soberania do Estado nacional, mostrando que, se o Estado se fortalecia, ao lado dele multiplicavam-se as associações, como os partidos políticos, as sociedades comerciais, as organizações científicas e artísticas, os sindicatos, as igrejas, as escolas e os clubes. Esses agrupamentos é que seriam, na sua perspectiva, verdadeiras unidades sociais, ocupando o lugar que, nas teorias tradicionais, era dado ao indivíduo isolado ou à suprema e simples organização política. O novo papel do Estado seria o de coordenador desse pluralismo. Na utopia deweyana, quando a filosofia cooperasse com o curso dos acontecimentos e tornasse claro e coerente os significados dos pormenores diários, haveriam de interpenetrar-se a ciência e a emoção, a prática e a imaginação. Na promoção dessa articulação, assim como na revelação dos significados do cotidiano, estava posto o problema da tarefa da filosofia em dias de transição. 
A transição de um mundo pré-científico, pré-tecnológico e pré-democrático para um mundo científico, tecnológico e democrático colocava problemas relativos à alienação do sujeito dos quais Dewey tinha aguda consciência. Ele reagia filosoficamente ao isolamento e à fragmentação crescente da vida social, defendendo, segundo Mills, a reinstauração de um tipo de sociabilidade perdida nas pequenas vilas americanas rurais que conhecera em sua adolescência, em uma espécie de fuga para trás, mas que não se identificava automaticamente com a defesa de um ruralismo retrógrado. Se Dewey recuava, Anísio fugiria para a frente em busca de uma democracia inexistente na sociedade brasileira. Esse movimento que se projeta ao contrário tem seu ponto de intersecção entre o antigo e o novo representado pela categoria de reconstrução, entendida justamente como a revisão da experiência anterior em qualquer campo (seja ele filosófico, religioso, político, pedagógico), colocada a serviço de novos ideais. Este foco cognoscitivo é também afetivo. Seu grau de abrangência permite não só uma reordenação da biografia, mas também a redefinição da história das instituições de que o sujeito participa projetando, nelas, outros significados.

Anísio inicia a divulgação das obras de Dewey no Brasil no final da década de 1920 e persiste até a década de 1950. Ele assumiu a crítica que Dewey realizou tanto à escola tradicional quanto à escola nova. $A$ escola tradicional nunca teria sido capaz de perceber que, junto ao objeto primário do seu ensino, pudessem ser aderidas outras possibilidades de aprendizagem e que, portanto, em uma simples lição de matemática para citar um exemplo - o professor poderia também estar ensinando a criança a ter complexos de inferioridade, a não ter coragem de enfrentar obstáculos e a não ser sociável, se a condenasse e humilhasse em suas observações. Ao enfatizar a preparação da criança para responsabilidades e privilégios da vida adulta, o professor poderia fazê-la perder impulso (pois a ela só interessa o presente), levá-la a adiar suas atividades, numa irresistível tentação de protelar suas tarefas (já que o futuro está longe), enquadrá-la num médio standard convencional e obrigá-la à utilização de falsos expedientes para manobrar penas e prazeres.

A escola nova como a escola tradicional são construções. Pode a primeira permanecer apenas no nome, principalmente se pretender reproduzir o ensino escolar como o ensino industrial, concebendo-o exclusivamente como ciência aplicada, insistindo em um planejamento excessivamente detalhado, ou ainda descuidar dos aspectos planejadores da 
atividade escolar, caindo no empirismo rasteiro e na improvisação desprovida de conteúdo sob a justificativa de uma liberdade (mal compreendida) da criança. Em um dos seus manuscritos, Anísio concebe a escola nova não como ruptura com a escola tradicional, mas como a subsistência dos seus aspectos positivos e uma reformulação didática. Procura definir, com precisão, sua concepção de trabalho produtivo:

é o trabalho a que se entrega o espírito quando faz a síntese entre antigas e novas representações, quando estabelece relação entre elas a fim de criar uma unidade superior. (Arquivo Anísio Teixeira, Manuscrito...)

Aí, como Dewey, identifica o processo educativo como o próprio processo de pensamento no sentido de reconstrução mental da experiência. Ao termo escola nova, Anísio prefere escola progressiva.

O pensamento de Dewey ajudou Anísio a desvencilhar-se da concepção de ligação estreita e rígida entre processo produtivo e processo escolar. Esse movimento é orientado por um afastamento calculado do modelo imposto pela Psicologia e uma aproximação, que em Anísio é efetiva, da Filosofia e da Arte. Daí a sua recusa à metáfora da escola como fábrica, na qual as ordens de serviço seriam emitidas pelos diretores, assistentes, inspetores, até atingirem o professor que executaria fielmente a tarefa. Em conseqüência, também a crítica ao perigo representado pelo endeusamento da ciência na organização e funcionamento escolar como algo problemático, que dificultava a visão da escola em seu conjunto. A grande renovação escolar passaria pelo fato de a criança desejar receber o conhecimento e trabalhar pessoalmente para conquistá-lo (idem, ibidem). Só essa atitude formaria, em sua visão, o caráter humano.

Nos anos 20, a discussão que Anísio empreende da democracia se faz sob bases filosóficas em um discurso bastante geral. Só na década de 1930 essa discussão ganhará a consistência da experiência de gestão vivida no Distrito Federal. A interlocução de Dewey com os países socialistas, sua crítica ao liberalismo e sua reflexão sobre o papel da religião só seriam divulgadas publicamente por meio das obras traduzidas no Brasil nas décadas de 1950 e 1960, embora Anísio já tivesse acesso a boa parte delas nas décadas de 1930 e 1940. Em síntese, a grande direção que the ofereceu Dewey e que socializou mais amplamente, na década de 1930, foi a concepção de que a educação pela qual valeria a pena lutar seria aquela 
que libertasse, num movimento progressivo, tal como ele o vivera, a capacidade individual para fins sociais cada vez mais amplos, mais livres e mais frutíferos. Só um regime democrático poderia realizar tal tarefa.

\section{A educação como foco de trabalho}

A obra de Anísio Teixeira é resultado da eleição da educação como foco de trabalho. Sua motivação em torno desse foco torna-se um campo de significado justamente pela sua persistência. Como explicar essa paixão pela educação? A rigor, a paixão não se explica. Vive-se. Ela se coloca, até para quem a vive, como mistério, cuja força leva o sujeito a responder às provocações da vida. Anísio Teixeira respondeu a essas provocações, lapidando o seu destino de educador no diálogo com os diversos educadores que dentro dele transitaram, na intensa experiência dos exercícios espirituais realizados na juventude, nas reflexões suscitadas pelas viagens, nas saborosas amizades.

A obra de Anísio Teixeira não é mais dele, aliás, nunca foi. Ela se confunde com o trabalho de seus colaboradores, de seus amigos, de todos os professores e pesquisadores que, nas salas de aula, nos laboratórios, nas oficinas, procuram reencantar a educação, criando situações que valorizam as perguntas, despertam a dignidade de que somos todos portadores, embora nem sempre a exerçamos, e reforçam o sentimento de que a solidariedade é possível e desejável. Mais forte que ele, me ensinam os que com ele conviveram e outros que também estudaram a sua obra, foi a sua denúncia de que a privação da educação torna impossível até a simples sobrevivência. Foi o seu alerta de que sem a qualidade cognitiva e social das experiências de conhecimento não existem vivências da esperança. E a escola, tal como ele e seus colaboradores pensaram e criaram, pretendia instituir-se como organizadora da esperança em vidas humanas concretas. Mas a organização da esperança assusta, porque desestabiliza o estabelecido, porque exige a paciência dos recomeços e a resistência para atravessar desertos.

Em sua vasta e importante obra, Anísio Teixeira tratou dos mais diversos temas da política da educação: o financiamento, a organização de um sistema público de ensino, a formação e aperfeiçoamento docente, a gestão da educação pública, os deveres da União e dos estados com relação à educação, a constituição da universidade pública e de sua autonomia, a democratização das oportunidades de acesso e permanência 
na escola fundamental, o planejamento da educação, a descentralização do sistema educacional, a qualidade dos serviços educacionais, a criação e valorização de cursos de pós-graduação em educação. Diversas iniciativas a eles relacionadas fizeram parte das reformas de educação que conduziu. Para ele e seus contemporâneos, a expressão reforma da educação enfeixava um conjunto de transformações sociais visando à diminuição de privilégios, hierarquias e desigualdades, mas será que, hoje, mantém esse significado? Creio que hoje a palavra reforma, amalgamada a termos como "flexibilidade", "globalização", "desregulamentação", dentre outros, sinaliza um conjunto de mudanças institucionais e estruturais orientadas justamente no sentido oposto, para o reforço dos privilégios e das desigualdades. A quem interessaria esquecer o que significa tratar da educação na esfera pública? (Silva 1996, p. 83).

Os argumentos ético-filosóficos em favor da privatização, que os antigos educadores católicos, contemporâneos de Anísio, tanto defenderam, como o célebre direito de a família educar seus filhos, ou mesmo a pluralidade ideológica e religiosa, vêm sendo ressignificados pela racionalidade administrativa e econômica que dá ênfase à qualidade de ensino. A face menos explícita da autonomia que a escola brasileira hoje goza quanto à sua proposta pedagógica, garantida pela nova Lei de Diretrizes e Bases (1996), é a que institui os estabelecimentos de ensino como ponto de partida das dinâmicas de concorrência e da escolha dos pais. É preciso que se enfatize, então, que essa escolha é realizada apenas pelos que podem economicamente e culturalmente fazê-la. Se a qualidade da educação está vinculada à distribuição de recursos materiais e simbólicos, receber uma educação de qualidade, na perspectiva neoliberal, é receber uma educação de mais qualidade do que outros. Vale, portanto, a advertência de que, ao invés da comparação das escolas, a comparação a ser feita é entre as diferentes escolarizações recebidas por grupos sociais desigualmente posicionados em nossa sociedade (idem, p. 85).

O embate entre os defensores da escola pública e os privatistas, hoje, coloca novas questões, como, por exemplo: seria oportuno introduzir a democracia no setor privado com subsídios para as escolas particulares ou definir uma estratégia de introduzir o dinamismo do setor privado no setor público mediante a descentralização e a autonomia de cada unidade escolar? Essa pergunta tem no fundo a crença do sucesso da escola particular do ponto de vista do produto que oferece ao mercado, embora pesquisas nem sempre muito divulgadas mostrem que este alegado êxito 
não corresponde a custos baixos ou a maior qualidade quando se compara a escola pública com a particular (Zibas 1997, p. 68).

A qualidade defendida pelo neoliberalismo, hoje, é tecnocrática, gerencial, pragmática no sentido restrito e se choca contra uma tradição, que Anísio Teixeira representa, na qual a qualidade é uma concepção política, democrática, substantiva, erigida em uma história de luta, dentro e fora do Estado, contra as exclusões e as discriminações e que procurou colocar os recursos materiais e simbólicos aos jovens que sofreram a sonegação desses mesmos recursos.

O discurso neoliberal é, sem dúvida, um processo poderoso, mas não podemos esquecer que as políticas globalizadoras, presentes em um mesmo quadro discursivo e mediante projetos semelhantes em vários países, não são propriamente idênticas, pois inexiste - e a análise histórica mostra isso - correspondência perfeita entre as reformas pretendidas e as executadas, mesmo quando as opções políticas se encontram subordinadas à orientação global. O peso das tradições culturais nacionais, os constrangimentos próprios de cada contexto de escolarização, o trabalho de reinterpretação dos atores no campo escolar em cada nível, desde o mais alto centro de decisão até a sala de aula, não podem ser menosprezados. Talvez fosse oportuno considerar não propriamente a globalização das políticas, mas a sua hibridização (Zaten e Ball 2000, pp. 1-20).

Mais do que nunca, vale resgatar, nesse momento, através de Anísio Teixeira, a nossa tradição democratizante e com ela a nossa história de enfrentamento dos interesses reacionários e conservadores contra a efetivação do direito à educação em nosso país e a favor de uma pedagogia da esfera pública. Vale resgatar a concepção da escola como construção social de diversos agentes, o que impulsionou Anísio a provocar, nos anos 50, através do CBPE e dos Centros Regionais, o diálogo entre educadores e cientistas sociais com o objetivo de instituir a educação como objeto de investigação e investi-la da dignidade acadêmica, o que a universidade elitista Ihe recusava. Essas lições são inesquecíveis e, nesse sentido, a obra de Anísio é, para além dos resultados, um núcleo de reflexão que se abre incessantemente de forma original. É o sentido que dela fazemos, as representações que dela construímos e onde palpitam os valores que abraçamos.

Apresentar Anísio Teixeira como nosso contemporâneo é elogiar a sua obra pela atualidade das questões e a clareza de propósitos e 
tratamento com que foram apresentadas e discutidas. É também não aceitar passivamente o sucateamento dos serviços públicos prestados à população, dentre os quais a educação se inclui, a desonestidade de interesses espúrios que desviam verbas públicas e renegam a justiça social como princípio, a arrogância da universidade quando seus intelectuais, em nome da competência específica, desvalorizam a educação como objeto de investigação e conhecimento e abdicam do exame das suas questões no presente.

Afirmar a contemporaneidade de Anísio é partilhar com ele a convicção de que, em nosso país, muito se falou de educação e muito pouco se realizou, o que dá a impressão penosa de que estamos sempre a nos repetir. Que esse desespero mudo pela ação não nos bloqueie ou estreite, de um modo oportunista, a nossa compreensão dos problemas da educação, nem não nos remeta a um saudosismo do passado, mas ao contrário, que nos obrigue a uma recuperação sistemática dos projetos e iniciativas que fazem parte da nossa herança social e cultural e que nos mobilizem a pensar o nosso momento histórico.

Assumir a contemporaneidade de Anísio é indignar-se, como ele se indignou, com a miséria humana. Por tudo que pensou, difundiu e realizou, ele nos convida a sacudir o conforto dos lugares instituídos e a assumir a nossa responsabilidade social como seres humanos e profissionais da educação diante desse fato. Celebrar a presença viva de Anísio entre nós, nesse instante, exige colocar em relevo, como ele o fez, não a própria pessoa, mas a educação e mais propriamente a escola. Apesar de uma realidade adversa, creio ser perfeitamente possível construir uma outra cultura em termos de ensino público que não seja a cultura da lamúria, mas uma cultura de realizações, mesmo que modestas, mas honestas, dignas e que façam, portanto, avançar o processo de universalização do ensino. A meta ainda é a maioridade do povo brasileiro não só pela valorização da cultura popular, mas também pela sua transformação em instrumento efetivo de construção da sua autonomia.

O futuro das novas gerações pelas quais Anísio Teixeira tanto lutou, sobretudo com a palavra justa, no sentido da pertinência conceitual, da gramática política e da justiça social, não pode ser entregue ao mercado. Quando escreveu Educação não é privilégio, livro que tanta polêmica causou, e cuja história reconstituí no texto que escrevi como posfácio, no relançamento dessa obra, em 1994, Anísio chama atenção para a importância do comprometimento da sociedade e dos poderes públicos com a edu- 
cação brasileira. Esse compromisso é, ainda hoje, uma questão de sobrevivência social, cultural e política. Como ele nos mostrou, o preço do reacionarismo e do conservadorismo, cultivados em estreitas e egoístas reivindicações pessoais, que impedem a visão da democracia como uma filosofia política e da educação como um campo de esforços para a sua realização, nunca é inocente.

Recebido para publicação em Setembro de 2000.

\section{Anísio Teixeira: Defending education as a universal right} ABSTRACT: The objective this article is to look back on Anísio Teixeira's life and work (1900-1971), on the $100^{\text {th }}$ anniversary of his birth, including decisive moments in his biography, his motivations as an educator, different aspects of his appropriation of John Dewey's work, and the usefulness of his conceptions for reflecting on contemporary Brazilian education.

Key words: Brazilian education, Brazilian educational thinking, biographies of educators

\section{Bibliografia}

ALMEIDA, S.B. de (org.). Chaves para ler Anísio Teixeira. Salvador: EGBA/ UFBA, 1990.

ANDERSON, P. "As afinidades de Norberto Bobio". Novos Estudos, 24, jul., 1989.

ASSMANN, H. Metáforas novas para reencantar a educação - Epistemologia e didática. Piracicaba: Editora da UNIMEP, 1996.

DEWEY, J. Liberdade e cultura. Rio de Janeiro: Folha Carioca, 1953. . Como pensamos (como se relaciona o pensamento reflexivo com o processo educativo). São Paulo: Nacional, 1959.

. Democracia e educação (introdução à Filosofia da Educação). São Paulo: Nacional, 1959.

. Experiência e educação. São Paulo: Nacional, 1976.

. Experiência e natureza, Lógica - A teoria da investigação, $A$ arte como experiência. Coleção Os Pensadores, 40. São Paulo: Abril Cultural, 1974. 
ECO, U. Obra aberta (forma e indeterminação nas poéticas contemporâneas). São Paulo: Perspectiva, 1971.

FERNANDES, F. "Anísio Teixeira e a luta pela escola pública". In: ROCHA, J.A. de L., Anísio em movimento: a vida e as lutas de Anísio Teixeira pela escola pública e pela cultura no Brasil. Salvador: Fundação Anísio Teixeira, 1992.

LOURENÇO FILHO. A propósito do centenário de John Dewey. Arquivo Lourenço Filho, série Produção Intelectual, LF 59.00.00/1, CPDOC/ FGV.

NUNES, C. "Prioridade número um para a educação popular". In: TEIXEIRA, A. Educação não é privilégio. Rio de Janeiro: Editora da UFRJ, 1994. . Apresentação. In: TEIXEIRA, A. Educação é um direito. Rio de Janeiro: Editora da UFRJ, 1996.

. Anísio Teixeira (verbete). In: FÁVERO, M. de L. de A. e BRITTO, J. de M. Dicionário de educadores no Brasil - Da colônia aos dias atuais. Brasília: MEC/INEP; Rio de Janeiro: Editora da UFRJ, 1999. . "(Des)encantos da modernidade pedagógica". In: Teixeira, E.M. et al. 500 anos de educação no Brasil. Belo Horizonte: Autêntica, 2000.

. Anísio Teixeira: a poesia da ação. São Paulo: EDUSF, 2000.

MENDONÇA, A.W.P.C. Universidade e formação de professores: uma perspectiva integradora. A universidade de Educação de Anísio Teixeira. Tese de doutoramento. Rio de Janeiro, Departamento de Educação da PUC-Rio, 1993.

MILLS, C. W. Sociology and pragmatism. Nova lorque: Oxford University Press, 1966.

ROCHA, J.A. de L. (org.). Anísio em movimento: a vida e as lutas de Anísio Teixeira pela escola pública e pela cultura no Brasil. Salvador: Fundação Anísio Teixeira, 1992.

SILVA, T.T. da. "O projeto educacional da 'nova' direita e a retórica da qualidade total". Universidade e Sociedade, 6 (10): 82-89, jan., 1996.

TEIXEIRA, A. Notas de aula de Anísio Teixeira no Teachers College. Arquivo Anísio Teixeira, série Temáticos, AT 27.01.06 t, documentos 3, 14, 15, 16, 17, 19 e 22, CPDOC/FGV. 
TEIXEIRA, A. Manuscrito sobre a escola, o conhecimento e a aprendizagem. Arquivo Anísio Teixeira, série Produção Intelectual, [Teixeira, A.] PI 24/ 29.00.00/2, CPDOC/FGV.

- "Por uma escola primária organizada e séria para formação básica do povo brasileiro". Educação e Ciências Sociais, 3(8): 139-141, 1958. . "O problema da formação do magistério". Documenta, (62): 5-15, nov., 1966.

. "Ciência e arte de educar". In: ROCHA, J.A. de L., Anísio em movimento. Salvador: Fundação Anísio Teixeira, 1992.

. Educação não é privilégio. Rio de Janeiro: Editora da UFRJ, 1994.

. Educação é um direito. Rio de Janeiro: Editora da UFRJ, 1996.

VIANNA, A. e FRAIZ, P. Conversa entre amigos - Correspondência escolhida entre Anísio Teixeira e Monteiro Lobato. Rio de Janeiro/Salvador: FGV/ CPDOC e Fundação Cultural do Estado da Bahia, 1986.

VIANA FILHO, L. Anísio Teixeira - A polêmica da educação. Rio de Janeiro: Nova Fronteira, 1990.

XAVIER, L.N. O Brasil como laboratório - Educação e ciências sociais no projeto dos Centros Brasileiros de Pesquisas Educacionais CBPE/ INEP/MEC (1950-1960). Bragança Paulista: EDUSF, 2000.

ZANTEN, A. van e BALL, S. "Comparer pour comprendre: globalisation, réinterprétations nationales et recontextualisations locales des politiques éducatives néolibérales". Revue de l'Institut de Sociologie. Bruxelas, 2000, mimeo.

ZIBAS, D.M.L. "Escola pública versus escola privada: o fim da história?". Cadernos de Pesquisa, (100): 57-77, mar., 1997. 